\title{
APPLICATION OF DIGITAL IMAGE CORRELATION IN INVESTIGATING THE BOND BETWEEN FRP AND MASONRY
}

\author{
Bahman Ghiassi' ${ }^{1}$, Jose Xavier ${ }^{2}$, Daniel V. Oliveira ${ }^{3}$, Paulo B. Lourenço ${ }^{4}$
}

\begin{abstract}
Full characterization of the bond behavior between Fiber Reinforced Polymers (FRPs) and masonry in externally bonded reinforcement (EBR) technique is crucial at the design stage or structural performance prediction. In this regard, a full-field assessment technique seems to be valuable for an adequate characterization of the bond behavior.

The digital image correlation (DIC) and feature tracking techniques have been used in this study for investigating the evolution of strains and deformation during uniaxial tensile tests and shear debonding tests in FRP-masonry systems. The results show that the DIC is a valuable technique for characterization of the bond behavior and investigating its three-dimensional aspects. The DIC was also found applicable for following the matrix crack development in Steel
\end{abstract}

${ }^{1} \mathrm{PhD}$ Student, ISISE, University of Minho, Department of Civil Engineering, Azurém, 4800-058 Guimarães, Portugal. Phone: +351 253510 499, fax: +351 253510 217, E-mail:

bahmanghiassi@civil.uminho.pt

${ }^{2}$ Research assistant, CITAB, University of Trás-os-Montes e Alto Douro, Vila Real, Portugal, jmcx@utad.pt

${ }^{3}$ Associate Professor, ISISE, University of Minho, Department of Civil Engineering, Azurém, 4800-058 Guimarães, Portugal. Phone: +351 253510 247, fax: +351 253510 217, E-mail:

danvco@civil.uminho.pt

${ }^{4}$ Professor, ISISE, University of Minho, Department of Civil Engineering, Azurém, 4800-058

Guimarães, Portugal. Phone: +351 253510 209, fax: +351 253510 217, E-mail:

pbl@civil.uminho.pt 
Reinforced Grout (SRG) specimens. Feature tracking method was used for monitoring the strains development on the steel fibers in SRG specimens during tensile tests. 


\section{Introduction}

Composite materials such as Fiber Reinforced Polymers (FRPs) or Steel Reinforced Grouts have been extensively used for external strengthening of masonry structures. The effectiveness of this strengthening technique is intrinsically dependent on the bond performance between the composite material and the masonry substrate. As the bond is a key mechanism in transferring the stresses from the structural element to the composite material, any bond loss leads to deterioration of the strengthening system and possible premature failure. Therefore, complete understanding of the governing bond mechanisms is necessary for design and quality control purposes.

Significant progress has been achieved in the last years regarding experimental and computational investigation of the debonding mechanism and damage in FRP-strengthened masonry elements [1-6]. However, aspects such as failure initiation, effective bond length, distribution of interfacial strains, the role of mortar joints and three-dimensional nature of the bond behavior require further investigation. A comprehensive bond-slip model, for numerical modeling approaches, is also missing for FRP-masonry systems. The bond-slip law can be experimentally obtained during the debonding tests from the distribution of strains, obtained from the strain gauges attached to the FRP's surface, along the bonded length [2]. However, the measurements are limited to the location of the strain gauges [2] and the bond behavior cannot be investigated precisely.

Use of a full-field measurement technique seems to be valuable in better understanding the above mentioned aspects of the bond behavior. This paper addresses the applicability of the optical measurement techniques for characterization of the tensile and bond behavior in FRPmasonry systems. For this reason, uniaxial tensile tests and shear debonding tests have been 
performed on previously prepared specimens and the evolution of strains on the specimens' surfaces has been measured with digital image correlation (DIC) and feature tracking methods. These methods have been widely used for measurement of displacements or strains in different fields of solid mechanics [7-9]. However, only a few studies can be found using these techniques for investigating the interfacial bond behavior, e.g. [10-11]. To the knowledge of authors, existing studies have been devoted to FRP-strengthened concrete elements and information on full-field assessment of bond in FRP-strengthened masonry has not been attempted.

Uniaxial tensile tests were performed here on Glass Fiber Reinforced Polymer (GFRP) and Steel Reinforced Grout (SRG) specimens. GFRP composites, compared with other conventional FRP materials, have lower axial stiffness which makes them more suitable for masonry structures. SRG has been chosen as a composite material with inorganic matrix that can be advantageous for strengthening masonry structures regarding compatibility and sustainability issues [2]. In GFRP composites, when prepared following the wet lay-up procedure, a complex strain distribution is expected along the specimen due to the non-uniform distribution of fibers along the width and length of the specimens. Information on strain distribution is useful for interpretation of the results obtained in debonding tests. In SRG composites, the interfacial strains do not seem to be transferred completely to the matrix (mortar) surface. Therefore, strain gauges attached to the mortar surface cannot provide a precise estimation of the interfacial strains. These issues have been investigated here with DIC and feature tracking methods.

In addition, single-lap shear bond tests have been performed on GFRP-strengthened brick specimens and the strain development along the bonded length has been investigated with the same technique. The full-field strain distribution on the FRP's surface and the three-dimensional aspects of the bond behavior have been also investigated. Specimens consisted of solid clay 
bricks strengthened with GFRP sheets following the wet lay-up procedure. Although recent studies have shown that the weak mortar joints can affect the bond behavior [4-5], this issue is not well known yet. Moreover, it seems that this effect varies with material (FRP and brick) and geometrical properties [4]. Therefore, the mortar joints are neglected in this study and it is assumed that the bond strength is fully utilized on the brick's surfaces. Meanwhile, characterization of the bond behavior between FRP and masonry pillar with the DIC method is being under investigation and the results will be presented and discussed elsewhere.

\section{Digital image correlation}

\subsection{Principle}

In the last decades, several interferometric and white-light optical methods have been proposed and developed in experimental solid mechanics [7,9]. These techniques contrast with conventional strain gauges or extensometers by the fact that they provide full-field data and are contact-free. Among these techniques, non-interferometric methods based on image processing, such as the DIC, have been increasingly used [12-13].

DIC-2D provides full-field displacements of a planar object by comparing the similarity between image features recorded at different mechanical states. The surface of interest must have a speckled pattern. Typically, this is obtained by spray or airbrush painting. A suitable balance between region of interest (ROI) and average size of white-to-dark spots must be achieved in order to enhance the displacement spatial resolution (small aperture) associated to the DIC measurements. In the DIC method, the displacement field is measured by analyzing the geometrical deformation of facets defined across the ROI. Therefore, the facet size defines the 
displacement spatial resolution. Typically, increasing the facet size improves the accuracy of the measurements but will degrade the spatial resolution.

\subsection{Measurements}

The specimens in the current testing program were prepared by applying a speckle pattern on the ROI, produced by applying a thin coating of white matt followed by a spread distribution of black dots using spray paint, see Fig.1. The ARAMIS DIC-2D software by GOM was used in this work [14-15]. The measurement system was equipped with an 8-bit Baumer Optronic FWX20 camera coupled with a Nikon AF Micro-Nikkor 200mm f/4D IF-EDlens

\section{(Table 1).}

In the test set-up, the optical system was positioned facing the surface of the specimen. A laser pointer was used to guarantee the correct alignment of the camera with regards to the specimen. The working distance (defined between the target surface and the support of the cameras) was set about $1.8 \mathrm{~m}$ leading to a conversion factor of $0.037 \mathrm{~mm}$.pixel ${ }^{-1}$, see Table $\mathbf{1}$. The aperture of the lens was completely open (minimum depth of field) in order to focus the image on the specimen's surface. The lens aperture was then closed to $f / 11$ in order to improve the depth of field during the testing. The shutter time was set to $5 \mathrm{~ms}$. The light source was finally adjusted in order to guarantee an even illumination of the target surface and to avoid overexposition.

Regarding the size of the ROI, the optical system (magnification) and the quality of the granulate (average speckle size) obtained by the spray paint, a facet size of $15 \times 15$ pixels $^{2}$ was chosen in this study. The facet step was also set to $15 \times 15$ pixels $^{2}$ in order to avoid statistically correlated measurements. The in-plane displacements were then numerically differentiated in 
order to determine the strains field. The typical resolution of the measurements was in the range of $10^{-2} \mathrm{~mm}$ and $0.02-0.04 \%$ for displacement and strain evaluation, respectively.

\section{Feature tracking method}

In the feature tracking method, the displacements of several target objects on a surface of interest are determined by suitable image tracking algorithms. This method only requires few marks (local features) over the ROI, which can be painted over a background surface. Normally, this technique does not have the same spatial resolution as the DIC method, but can be suitable for measuring the strains over uniform or moderate gradient fields [8].

The feature tracking method used in this work was based on image processing and analysis [16]. Since uniform strain/stress fields were expected in this study over the ROI, the low spatial resolution of this approach was not critical. The technique is based on the image tracking of the centroid of the target objects. The strain state in the material can be estimated by computing the change in the relative length among adjacent target points generated during deformation. Between the reference $(0)$ and a given deformed configuration $(t)$, the in-plane linear strains ( $\varepsilon_{\beta, 0-t}$ with $\beta=x, y$ directions) can be estimated as follows, see Fig.2(a):

$\mathcal{E}_{\beta, 0-t}=\frac{1}{n_{\beta}-1} \sum_{i=1}^{n_{\beta}-1}\left(\frac{L_{\beta, t}^{i, i+1}-L_{\beta, 0}^{i, i+1}}{L_{\beta, 0}^{i, i+1}}\right)=\frac{1}{n_{\beta}-1} \sum_{i=1}^{n_{\beta}-1}\left(\frac{\Delta L_{\beta, 0-t}^{i, i+1}}{L_{\beta, 0}^{i, i+1}}\right)$

where $\Delta L_{\beta, 0-t}^{i, i+1}$ represents the change of length between two adjacent marks, $L_{\beta, 0}^{i, i+1}$ is the initial length in the reference state between the same marks, and $n_{\beta}$ represents the total number of target points on the image along the $\beta$ direction.

In order to solve Eq. (1), the in-plane coordinates of the target marks $\left(x_{\beta}\right)$ have to be determined. The flowchart of the proposed algorithm is schematically shown in Fig.2(b). In the 
first step, images of the target objects have to be acquired before $(0)$ and after $(t)$ deformation. A camera-lens optical system with suitable magnification should be used. In practice, for enhancing contrast between the target objects (black) and the uniform substrate of the material (white) saturated images can be recorded. The recorded images can be cropped before post-processing to define a sub-image in which the target objects are limited. Therefore, regions outside the field of view (typically they correspond to dark zones of the surrounding environment) are systematically eliminated. These steps can be advantageous in image segmentation and classification, allowing a suitable definition of areas of target objects and background.

A transformation of a gray level image, $f(x, y)$, into the binary image, $g(x, y)$, was then performed by choosing a suitable threshold value $T$. In the binary image, pixels labeled "one" correspond to the target objects, while pixels set to "zero" are associated to the background. This classification is convenient for further image analysis. Morphological analysis applied to the binary images were deemed necessary because errors or imprecisions can occur in defining the target objects: $(i)$ the marks painted can be imaged with a pronounced variation of light intensity distribution, from which it can be difficult to define a single closed object in the image segmentation step; (ii) natural spots of the material reflected over the surface of the specimen may be imaged with a gray level intensity closer to the one of the target marks, resulting, after segmentation, into a binary image with parasite strains. This step consists of a combination of erosion and dilation in order to completely fill and define the target objects and/or get rid of erroneous strain regions in the background persisting after segmentation. Finally, for each image, the total number of target objects $\left(n_{\beta}\right)$ and their centroid location $\left(x_{\beta}\right)$ is obtained. From these coordinates, the distance between two adjacent points can be determined by: 
$L_{\beta}^{i, i+1}=\left|\bar{x}_{\beta}^{i+1}-\bar{x}_{\beta}^{i}\right| \quad\left(i=1, \ldots, n_{\beta}-1\right)$

where

$\bar{x}_{\beta}^{i}=\frac{1}{m} \sum_{j=1}^{m} x_{\beta_{j}}^{i}$

This information is used to solve Eq. (1) yielding an estimation of the strain state on $\mathrm{x}$ and $\mathrm{y}$ directions.

An example of a pattern suitable for applying the feature tracking method painted on the specimens is shown in Fig.3. Images were recorded during the tests with an acquisition rate of $1 \mathrm{~Hz}$ and image processing was applied to the entire set of images in order to determine an average strain applied to the material.

\section{Experimental program}

The experimental program includes tensile and shear bond tests. Tensile tests have been performed on aluminum, GFRP, and SRG specimens. Aluminum was chosen, as a homogenous and known material in which uniform distribution of strains and deformation are expected during the tensile tests, in order to provide a reference for the results obtained from other materials. Shear bond tests were performed on GFRP-strengthened masonry bricks. In both tests the DIC and feature tracking methods were used to measure the evolution of deformation.

Tensile tests specimens had $450 \mathrm{~mm}$ length and $40 \mathrm{~mm}$ width, see Fig.4. The aluminum plate had a thickness of $2 \mathrm{~mm}$. The GFRP coupon specimens were prepared following the wet lay-up procedure using unidirectional glass fibers (MapeWrap G UNI-AX) and a two part epoxy resin (MapeWrap 31). SRG specimens were prepared with a medium density steel fiber (FIDSTEEL 3x2 12-12-500 HARDWIRE) covered by a pozzolanic lime-based mortar (Albaria Struttura) with two different mortar thicknesses (6 and $10 \mathrm{~mm})$, chosen based on usual practice. 
Three specimens from each material were prepared and tested. Single-lap shear bond tests were performed on GFRP-strengthened brick specimens. The specimens were made of solid clay bricks with dimensions of 200x100x50 mm. GFRP sheets were applied to the bricks' surfaces with an epoxy resin (MapeWrap 31) following the wet lay-up procedure. The bricks were dried in the oven before application of the GFRP sheets. Then, a two-part epoxy primer (MapeWrap Primer 1) was applied to the bricks' surfaces for preparation of the substrate surface before GFRP application. Finally, a two-part epoxy resin (MapeWrap 31) was used as the matrix for the composite material and adhesion to the masonry substrate. The bonded length of the strips was equal to $150 \mathrm{~mm}$ with a $40 \mathrm{~mm}$ unbounded part at the loaded end, see Fig.5. Mechanical tests have been performed on materials constituents following relevant test standards [17-20] and the results are presented in Table 2.

The test setup used for performing the tensile tests is shown in Fig.6(a). The tests were performed using a universal testing machine with maximum load capacity of $200 \mathrm{kN}$ under displacement control conditions. The specimens were pulled monotonically with a constant velocity of $2 \mathrm{~mm} / \mathrm{min}$ corresponding to a mean strain rate, $\varepsilon$, of $7.5 \times 10^{-5} \mathrm{~s}^{-1}$. The DIC technique was used to measure the deformation on the surface of the aluminum plate, the GFRP coupon and the mortar in the SRG specimens. The deformation development in the steel fibers in SRG specimens was measured with the feature tracking method.

A testing apparatus with maximum load capacity of $50 \mathrm{kN}$ was used for conducting the single-lap shear bond tests, see Fig.6(b). A supporting frame was used to support the specimens appropriately and avoid misalignments in the load application. The specimens were pulled monotonically with a velocity of $0.3 \mathrm{~mm} / \mathrm{min}$. The tests were driven under displacement control using a LVDT placed at the loaded end of the FRP composite. The resulting load was measured 
by means of a load cell. The global slip between the GFRP and the masonry substrate was measured by means of two LVDTs mounted at the loaded end. The surface deformations and strains were determined with the DIC method.

\section{Results and discussion}

\subsection{Tensile tests}

The typical load-displacement behavior of the aluminum plates together with the longitudinal strain distributions measured with the DIC technique are shown in Fig.7. Uniform distribution of strains in the ROI can be observed, as expected. The evolution of strains with load increment and their uniform distribution along the specimen's length and width can be observed. The elastic modulus of the aluminum plate has been obtained as the initial slope of the stressstrain curve (from DIC measurements) equal to $60 \mathrm{GPa}$. The measured strain rate with the DIC technique was $7.5 \times 10^{-5} \mathrm{~s}^{-1}$ equal to the applied strain rate during the tests, being an evidence of the measurements accuracy and suitability of the applied speckle pattern and solution algorithms.

The typical tensile load-displacement behavior of GFRP coupons together with the longitudinal strain distributions measured with the DIC technique are shown in Fig.8. The GFRP coupons showed a linear behavior until failure, as expected. It can be observed that the distribution of strains along the GFRP coupon is not as uniform as the aluminum plate. The distribution of longitudinal, $\varepsilon_{\mathrm{x}}$, and transverse strains, $\varepsilon_{\mathrm{y}}$, are presented in Fig.9 at two different sections in the ROI for one tested specimen. Large fluctuations of longitudinal and transverse strains can be observed. The non-uniform distribution of fibers and matrix along the specimens' length and width, commonly observed in wet lay-up procedures, can produce such a complex distribution of strains. Moreover, imperfections due to application procedure together with the non-homogenous nature of this composite material can result in the observed strain localizations 
and fluctuations [21]. This observation becomes clearer when comparing the strains obtained in the aluminum plate and the GFRP coupon at the same load level, see Fig.10. On the other hand, large transversal strains are found in the GFRP specimen, which makes the stress states and failure complex, see Fig.9. The observed strain fluctuations and large transversal strains can affect the bond behavior between the GFRP sheet and masonry substrate in strengthened masonry elements, and this should be considered in the interpretation of experimental results. The variation of strains along the specimen's width and length shows that using local measurement instruments such as strain gauges may lead to inappropriate observations and conclusions. The elastic modulus of GFRP has been obtained as the initial slope of the stressstrain curve and is equal to $75 \mathrm{GPa}$. The measured strain rate with the DIC technique was again $7.5 \times 10^{-5} \mathrm{~s}^{-1}$ equal to the applied strain rate during the tests, showing the accuracy of the measurements.

The typical tensile load-displacement behavior of SRG specimens is shown in Fig.11 together with the longitudinal strain distributions on the mortar's surface. Strain localizations at the cracks locations can be observed in this figure. Cracks in the specimen with $6 \mathrm{~mm}$ mortar thickness (SRG-6) are well distributed along the surface while few large cracks occurred in the specimen with $10 \mathrm{~mm}$ mortar thickness (SRG-10). This difference, attributed to the bond behavior of steel fibers, is a known phenomenon in reinforced concrete elements [22]. The evolution of cracks on the mortar surface can be followed easily using the DIC technique, see Fig.12. The strain peaks correspond to the cracks locations and it can be observed that more cracks with lower peak strains are produced in the SRG-6 specimen, when compared to the SRG10 specimen. Moreover, the strains on the mortar surface in the uncracked regions can be negligible (particularly in the case of the SRG-10 specimen), meaning that the strains developed 
at the steel/mortar interface are practically not transferred to the mortar surface. Therefore, using strain gauges or DIC technique on the mortar surface in SRG-strengthened masonry elements can provide inaccurate estimations of interfacial strains and other techniques should be used for measurement of the strains on the steel fibers.

Since application of speckle pattern on the steel fibers is not possible, a feature tracking method has been used for obtaining the strains development in the steel fibers. For this reason, new SRG specimens were prepared with the geometrical details shown in Fig.13. The aim was to follow the development of strains in the steel fibers. The obtained stress-strain curve using the feature tracking method has been compared with the one obtained from LVDT in Fig.14. Moreover, knowing the applied stresses and elastic modulus of the steel fibers provided by the manufacturer (200 GPa), the strain in the steel fibers has been calculated with simple mechanical formulations at two stress levels. The good observed agreement shows the accuracy of the adopted feature tracking method. Therefore, this method can be a suitable solution for measurement of the global slip of the reinforcements during debonding tests in SRGstrengthened masonry elements.

\subsection{Single-lap shear debonding tests}

The typical force-slip response obtained from experimental tests is shown in Fig. 15. The distribution of strains along the bonded length, determined from the DIC measurements, is presented in Fig. 16. The evolution of strains along the bonded length with the load increment can be observed.

The longitudinal strains profiles are shown in Fig.17(b, c) at the FRP middle and edge sections, respectively. It can be observed that the strain distributions are different in these two sections, due to the boundary conditions [4]. Moreover, significant transversal strains appear 
near the loaded end at high load levels, see Fig.17(d). These observations confirm experimentally the three-dimensional nature of the debonding phenomenon, which is commonly neglected in design procedures and in the discussion of experimental results. It can be observed that the strain values increase suddenly moving forward from point $\mathrm{C}$ to $\mathrm{D}$ which is due to the initiation of debonding and crack propagation along the FRP bonded length. This is also observable in the force-slip diagram, Fig. 15, where the curve stiffness changes at point C. The observed fluctuations in the strain profiles can be partly attributed to the variation of the material properties and bond imperfections.

An important parameter that can be obtained from the strain profiles is the effective bond length $l_{e}$, defined as the length in which the stresses are fully transferred from the FRP composite to the substrate (i.e. the minimum length to achieve the maximum load) [10]. After the effective bond length, the strain values are negligible and therefore no stresses are transferred to the masonry. For obtaining the effective bond length, the average strain profile at failure (point $\mathrm{D}$ in Fig. 15) has been obtained, see Fig.18, by averaging the strain values over a $10 \mathrm{~mm}$ width strip at the middle of the FRP sheet. The average values have been used in order to reduce the effect of material variations [10] and it has been observed that the effective bond length obtained is not sensitive to the averaging width, as $(5,10$ and $15 \mathrm{~mm})$ widths were tested. The strain distribution is then approximated with a nonlinear expression by performing regression analysis. It was observed that an expression with the following type can be suitably simulate the strain distributions along the bonded length:

$$
\varepsilon(x)=A_{2}+\frac{A_{1}-A_{2}}{1+\left(\frac{x}{x_{0}}\right)^{p}}
$$


where $A_{2}, A_{1}, x_{0}, p$ are the constants to be determined from experimental results and $x$ is the distance from the loaded end. The predicted strain distribution is shown with a solid line in Fig.18. It can be seen that the bonded area consists of three main regions, as also observed in [10]. The FRP is fully debonded from the substrate near the loaded end. This is followed by a stress transfer zone, and after that no stress is transferred to the substrate. The length of the stress transfer zone, about $30 \mathrm{~mm}$ in this case (average of three tests), is then the effective bond length.

Finally, it is noted that the bond-slip laws in longitudinal and transversal directions can be obtained from the strain profiles [3]. The local bond stress-slip ( $\tau-s)$ curves can obtained from the experimental strain profiles measured along the FRP reinforcement at different load levels. In fact, the bond stress distribution within the bonded length can be evaluated by imposing the equilibrium condition of a FRP strip with a length $d \mathrm{x}$ bonded to masonry, assuming an elastic behavior of the reinforcement, as:

$\tau(x)=t_{f} E_{f} \frac{d \varepsilon_{f}}{d x}$

where $d \varepsilon_{f} / d x$ is the gradient of FRP strain along the sheet length, $E_{f}$ is the FRP elastic modulus, and $t_{f}$ is the FRP thickness. Moreover, the slip at distance $x$ from the free end of the specimen can be calculated assuming a zero slip in the free end as:

$$
s(x)=\int \varepsilon_{f} d x
$$

The local bond-slip behavior of the specimens near the loaded end have been obtained by means of Eqs. (4) and (5) using the strain distributions obtained from the DIC measurements, see Fig.19. For this reason, the strain profiles obtained from DIC measurements have been 
approximated with the same nonlinear model for different load levels, Fig.18. Then, the obtained mathematical formulation for each load level has been used in Eqs. (4) and (5) for calculating the spatial value of shear stress and slip. For obtaining an average bond-slip behavior, the values are presented for $10,15,18$, and $20 \mathrm{~mm}$ distances from the loaded end. It can be seen that the bondslip curve follow a trilinear trend with a plastic branch in the middle, solid line depicted in Fig.19. The tri-linear bond-slip behavior observed here has also been proposed for FRPstrengthened brick specimens in [3].

\section{Conclusions}

Digital image correlation and feature tracking methods were used in this paper for obtaining the full-field distribution of strains and displacements in tensile tests and single-lap shear debonding tests. The tensile tests were performed on aluminum, GFRP, and SRG coupon specimens. Aluminum was used as a homogenous material in which a uniform distribution of strains is expected during tensile tests. A non-uniform distribution of strains was observed in GFRP coupons during tensile tests. These non-uniformities can affect the bond behavior in FRPstrengthened masonry elements and should be considered in the interpretation of experimental results. In SRG specimens, localization of strains on the mortar surface at the cracks locations was observed. The measured strains on the other regions were negligible showing that the interfacial strains from the steel fibers might not fully transferred to the mortar surface, particularly if moderate mortar thicknesses are used. The feature tracking method was used for measurement of the strains on the steel fibers and the results were presented. It was observed that this technique is suitable for accurate measurement of steel fibers strains during tensile or debonding tests. 
The evolution of strains during the shear debonding tests was measured with the DIC technique. An advantage of DIC, when compared to conventional measurement techniques, is that a clear insight of distribution of strains can be obtained. This is much useful for investigating the three-dimensional aspects of the bond behavior and for characterizing bond-slip laws, which require a specific testing program. The results obtained showed also different longitudinal strain distributions along the bonded length at the FRP middle and edge sections. Moreover, large transversal strains were observed near the loaded end close to failure of the specimens, further confirming the three-dimensional nature of the bond behavior. Finally, it was shown how to calculate the effective bond length in GFRP-strengthened brick specimens from the DIC measurements and the obtained bond-slip behavior was presented.

\section{References}

[1] Oliveira D, Basilio I, Lourenço PB. Experimental bond behavior of FRP sheets glued on brick masonry. J Compos Constr, ASCE. 2011;15(1):32-41.

[2] Valluzzi MR, Oliveira DV, Caratelli A, Castori G, Corradi M, de Felice G, Garbin E, Garcia

D, Garmendia L, Grande E, Ianniruberto U, Kwiecień A, Leone M, Lignola GP, LourençoPB, Malena M, Micelli F, Panizza M, Papanicolaou CG, Prota A, Sacco E, Triantafillou TC, Viskovic A, Zając B, Zuccarino G. Round robin test for composite-to-brick shear bond characterization. Mater Struct 2012. doi 10.1617/s11527-012-9883-5.

[3] Ghiassi B, Marcari G, Oliveira DV, Lourenço PB. Numerical analysis of bond behavior between masonry bricks and composite materials. Eng Struct. 2012;43:210-20.

[4] Ghiassi B, Oliveira D, Lourenço PB, Marcari A. Numerical study of the role of mortar joints in the bond behavior of FRP-strengthened masonry. Compos B. 2012; 46:21-30. 
[5] Fedele R, Milani G. Assessment of bonding stresses between FRP sheets and masonry pillars during delamination tests. Compos B. 2012;43(4):1999-2011.

[6] Fedele R, Milani G. Three-dimensional effects induced by FRP-from-masonry delamination. Compos Struct 2011;93(7):1819-31.

[7] Xavier J, Sousa AMR, Morais JJL, Filipe VMJ, Vaz M. Measuring displacement fields by cross-correlation and a differential technique: experimental validation. Opt Eng 2012;51(4), 043602.

[8] Dahl K, Malo K. Planar strain measurements on wood specimens. Exp Mech. 2009;49(4):575-86.

[9] Sousa AMR, Xavier J, Vaz M, Morais J, Filipe VMJ. Cross-correlation and differential technique combination to determine displacement fields. Strain. 2011;47(S2):87-98.

[10] Carloni C, Subramaniam K. Investigation of the interface fracture during debonding between FRP and masonry. Adv Struct Eng 2009;12(5):731-43.

[11] Carloni C, Subramaniam K. Direct determination of cohesive stress transfer during debonding of FRP from concrete. Compos struct 2010;93:184-92.

[12] Sutton MA, Orteu JJ, Schreirer H. Image correlation for shape, motion and deformation measurements: Basic concepts, theory and applications: Springer; 2009.

[13] Pan B, Qian K, Xie H, Asundi A. Two-dimensional digital image correlation for in-plane displacement and strain measurement: a review. Meas Sci Technol. 2009;20(6):2001.

[14] ARAMIS user manual- Software- v6.0.2-6. 2009. 
[15] Xavier J, de Jesus A, Morais J, Pinto J. Stereovision measurements on evaluating the modulus of elasticity of wood by compression tests parallel to the grain. Constr Build Mater. $2012 ; 26: 207-15$.

[16] Xavier J, Custodio J, Morais J, Guedes R. Assessing mechanical properties of a polymer material by a video extensometer technique. In proc of 7th EUROMECH. Lisbon, Portugal 2009. p. $253-60$.

[17] EN 772-1. Methods of test for masonry units -Part 1: Determination of compressive strength; 2011.

[18] EN ISO 527-1. Plastics-determination of tensile properties- Part 1: general principles; 2012.

[19] EN 1015-11. Methods of test mortar for masonry Part 11: Determination of flexural and compressive strength of hardened mortar. 2007.

[20] ASTM D7565-10. Standard test method for determining tensile properties of fiber reinforced polymer matrix composites used for strengthening of civil structures; 2010. [21] Brynk T, Molak RM, Janiszewska M, Pakiela Z. Digital Image Correlation measurements as a tool of composites deformation description. Comput Mater Sci. 2012;64:157-61.

[22] Maekawa K, Pimanmas A, Okamura H. Nonlinear mechanics of reinforced concrete: Spon Press; 2003. 


\section{List of Tables}

Table 1. Optical system components and measurement parameters.

Table 2. Material mechanical properties.

\section{List of Figures}

Fig.1. Example of a speckle pattern and histogram of a GFRP coupon specimen.

Fig.2. Tracking method: (a) schema of the target objects; (b) flowchart of the proposed image feature-based algorithm.

Fig.3. Example of pattern used for the feature tracking method.

Fig.4. Details of the tensile specimens (dimensions in $\mathrm{mm}$ ).

Fig.5. Details of the specimens prepared for debonding tests (dimensions in $\mathrm{mm}$ ).

Fig.6. Tests setup: (a) Tensile tests; (b) Shear bond tests.

Fig.7. Tensile behavior of the aluminum plate (force-displacement diagram and strains in the ROI).

Fig.8. Tensile behavior of the GFRP coupon (force-displacement diagram and strains in the ROI).

Fig.9. Strain profiles in the GFRP coupon at different load levels (A to D in Fig.8): (a) speckle pattern; (b) strain profiles along line a-b; (c) strain profiles along line c-d.

Fig.10. Comparison of longitudinal strains along section c-d between GFRP coupon and aluminum plate for the same load level.

Fig.11. Load-displacement behavior of the SRG tensile specimens with different mortar thickness in mm (force-displacement diagram and strains in the ROI): (a) SRG-6; (b) SRG-10.

Fig.12. Longitudinal strains along section c-d in SRG tensile specimens at different load levels (A to D in Fig.11): (a) speckle pattern; (b) SRG-6 specimen; (c) SRG-10 specimen.

Fig.13. SRG specimens prepared for the feature tracking method (dimensions in $\mathrm{mm}$ ).

Fig.14. Comparison of strains developed on the steel fibers and mortar surface.

Fig. 15. Typical force-slip behavior of GFRP-strengthened specimen.

Fig. 16. Distribution of strains along the bonded area at different load levels (A to D in Fig. 15): (a) longitudinal strains (b) transversal strains.

Fig.17. Strain profiles in GFRP-strengthened brick specimen: (a) speckle pattern; (b) longitudinal strains along section $a-b ;$ (c) longitudinal strains along section $c-d ;(d)$ transversal strains along section c-d.

Fig.18. Average longitudinal strain along FRP middle section (sec. a-b in Fig.17) and the effective bond length $l_{e}$.

Fig.19. Bond-slip behavior of GFRP-strengthened brick. 
Table 1. Optical system components and measurement parameters.

\begin{tabular}{|c|c|}
\hline \multicolumn{2}{|l|}{ CCD camera } \\
\hline Model & $\begin{array}{l}\text { Baumer Optronic FWX20 } \\
\text { ( } 8 \text { bits, } 1624 \times 1236 \text { pixels, } 4.4 \mu \mathrm{m} / \text { pixel) }\end{array}$ \\
\hline Shutter time & $5 \mathrm{~ms}$ \\
\hline Acquisition frequency & $1 \mathrm{~Hz}$ \\
\hline \multicolumn{2}{|l|}{ Lens } \\
\hline Model & Nikon AF Micro-Nikkor 200mm f/4D \\
\hline Aperture & $f / 11$ \\
\hline Lighting & LEDMHL10 (color temperature: $6000 \mathrm{~K}$ ) \\
\hline Working distance & $1800 \mathrm{~mm}$ \\
\hline Conversion factor & $0.037 \mathrm{~mm} /$ pixel \\
\hline \multicolumn{2}{|l|}{ Project parameter - Facet } \\
\hline Facet size & $15 \times 15$ pixel $^{2}$ \\
\hline Step size & $15 \times 15$ pixel $^{2}$ \\
\hline \multicolumn{2}{|l|}{ Project parameter - Strain } \\
\hline Computation size & $7 \times 7$ facets \\
\hline Validity code & $55 \%$ \\
\hline Strain computation method & Total \\
\hline Image recording & \\
\hline Acquisition frequency & $1 \mathrm{~Hz}$ \\
\hline
\end{tabular}


Table 2. Material mechanical properties.

\begin{tabular}{lccc}
\hline Masonry brick & & & $\mathrm{CoV}(\%)$ \\
\hline Compressive strength & $f_{\mathrm{cb}}(\mathrm{MPa})$ & 9.10 & 15.7 \\
Flexural tensile strength & $f_{\mathrm{tb}}(\mathrm{MPa})$ & 1.54 & 24.6 \\
Elastic modulus & $E_{\mathrm{b}}(\mathrm{GPa})$ & 1.73 & 21.4 \\
\hline GFRP coupons & & & \\
\hline Tensile strength & $f_{\mathrm{tf}}(\mathrm{MPa})$ & 1250 & 15.0 \\
Elastic modulus & $E_{\mathrm{f}}(\mathrm{GPa})$ & 75.0 & 8.2 \\
Ultimate deformation & $\varepsilon(\%)$ & 3.0 & 20.2 \\
\hline Epoxy resin & & & \\
\hline Tensile strength & $f_{\mathrm{tm}}(\mathrm{MPa})$ & 53.8 & 9.7 \\
Elastic modulus & $E_{\mathrm{m}}(\mathrm{GPa})$ & 2.52 & 9.5 \\
\hline Primer & & & \\
\hline Tensile strength & $f_{\mathrm{tm}}(\mathrm{MPa})$ & 34.4 & 11.1 \\
Elastic modulus & $E_{\mathrm{m}}(\mathrm{GPa})$ & 2.36 & 6.1 \\
\hline Mortar & & & \\
\hline Compressive strength $(28$ days $)$ & $f_{\mathrm{cm}}(\mathrm{MPa})$ & 12.7 & 10.1 \\
\hline Steel fibers & & & \\
\hline Tensile strength & $f_{\mathrm{ts}}(\mathrm{MPa})$ & 2980 & 2.9
\end{tabular}



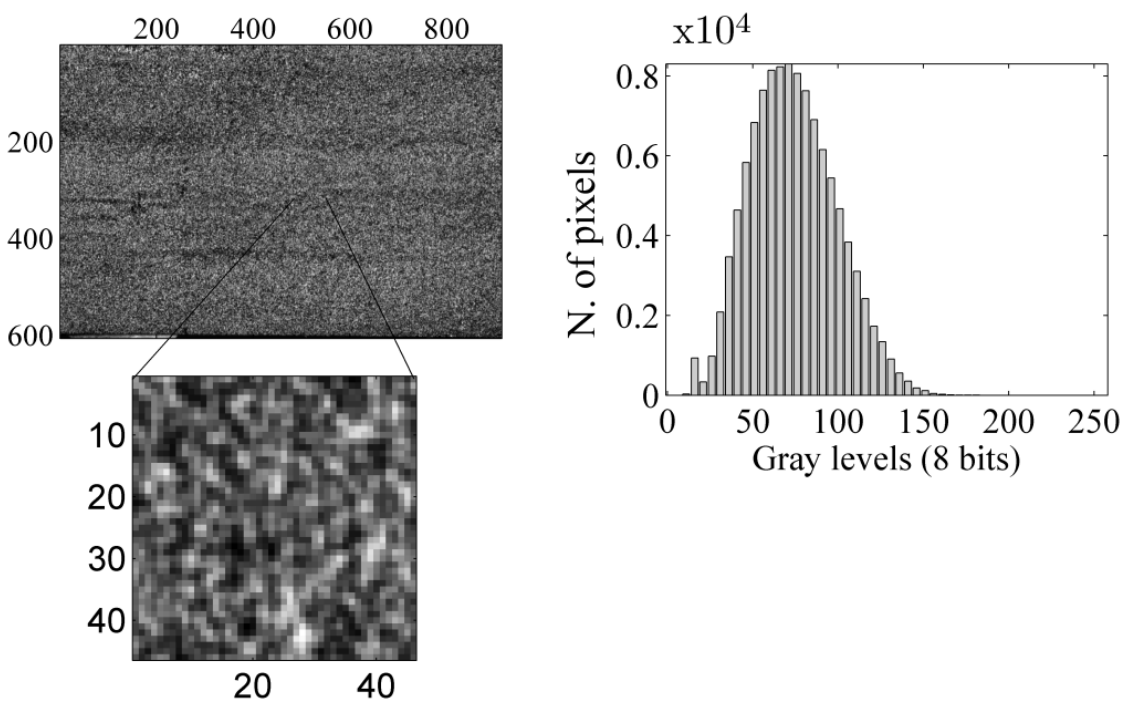

Fig.1. Example of a speckle pattern and histogram of a GFRP coupon specimen. 

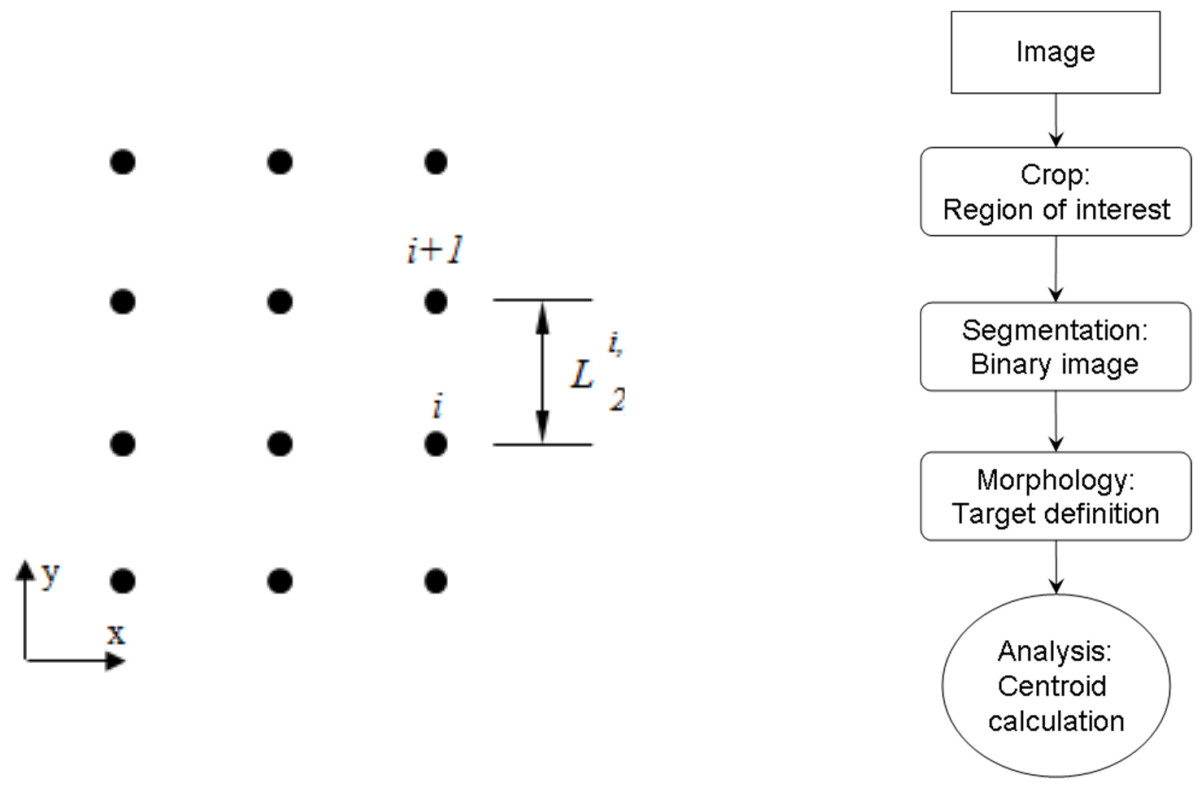

(a)

(b)

Fig.2. Tracking method: (a) schema of the target objects; (b) flowchart of the proposed image feature-based algorithm. 


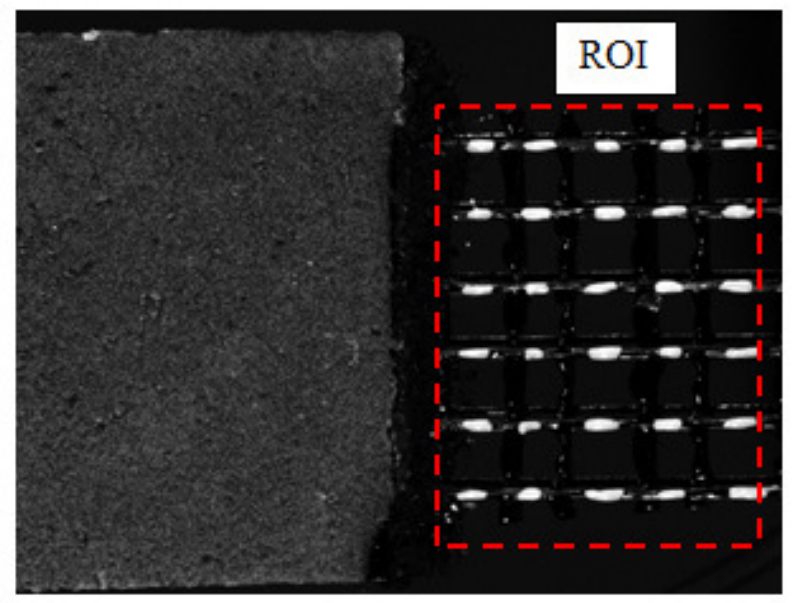

Fig.3. Example of pattern used for the feature tracking method. 

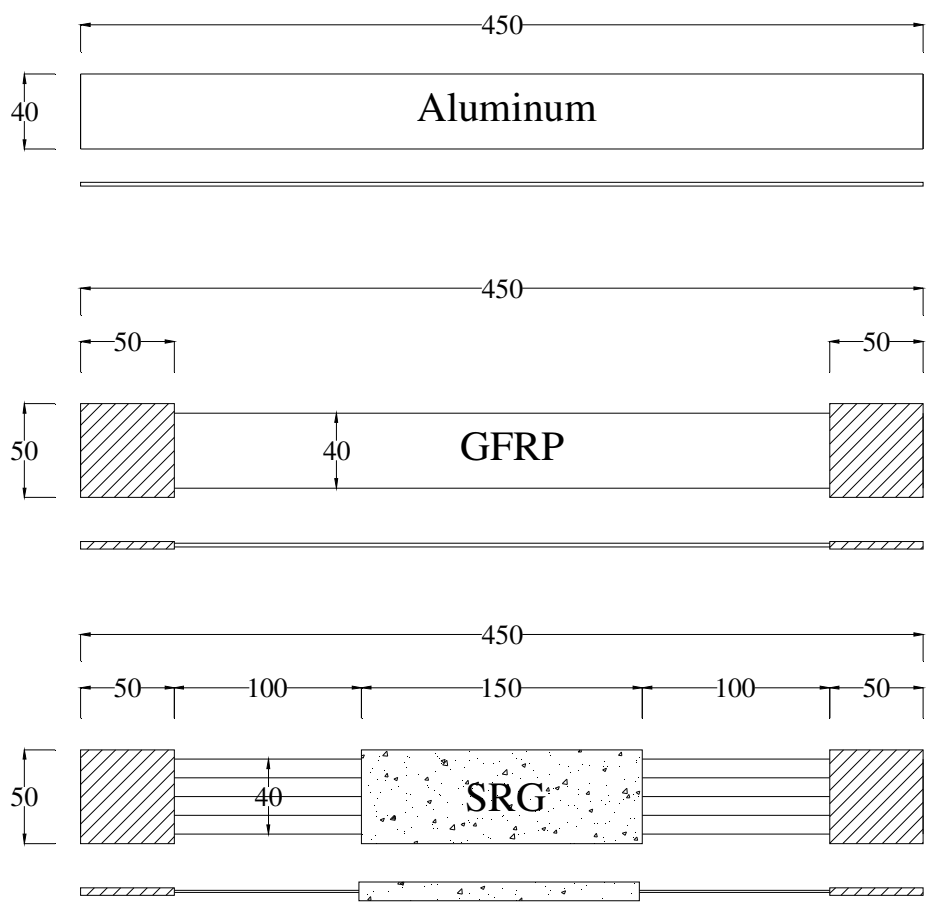

Fig.4. Details of the tensile specimens (dimensions in $\mathrm{mm}$ ). 


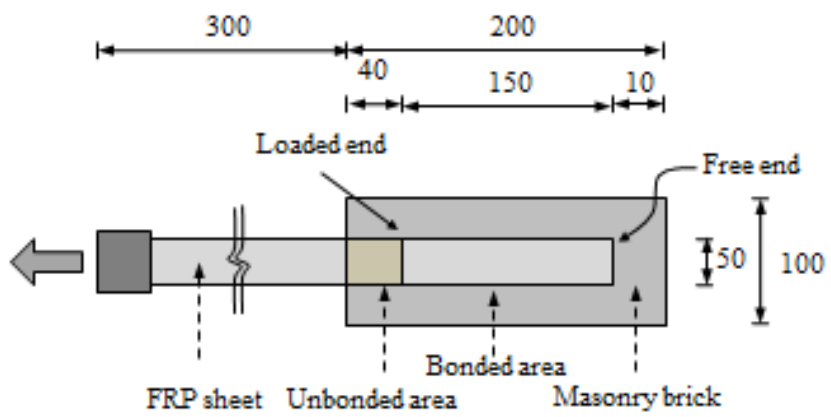

Fig.5. Details of the specimens prepared for debonding tests (dimensions in mm). 


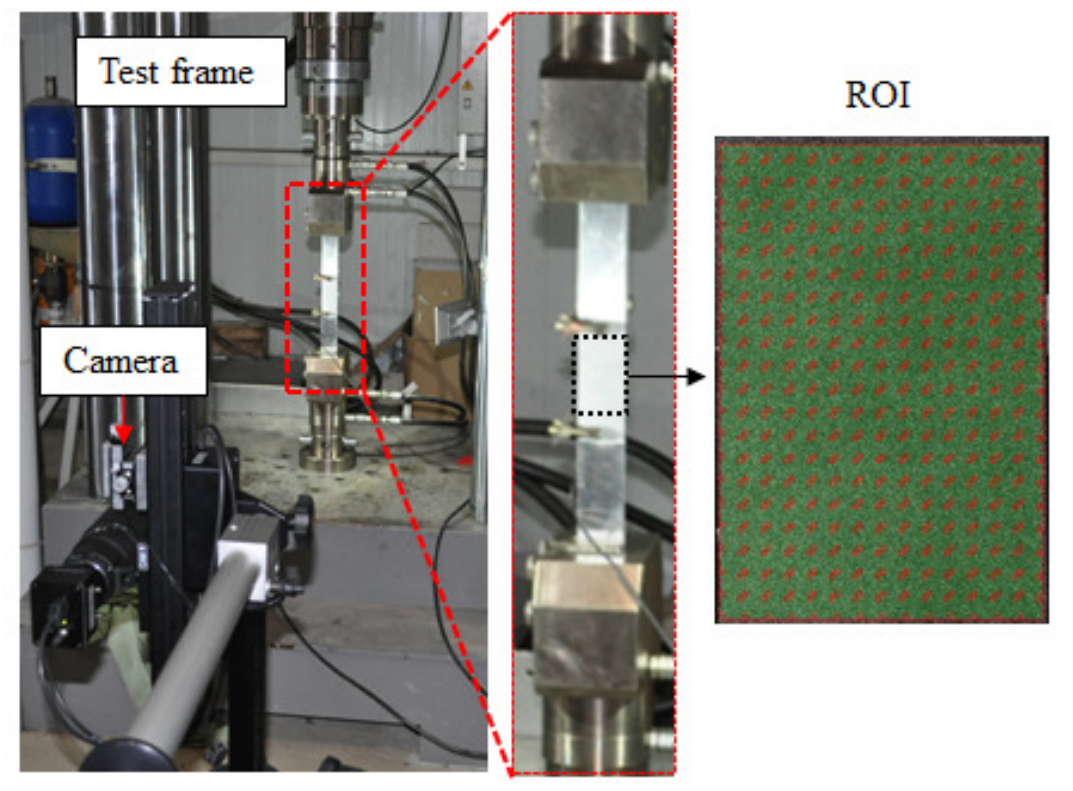

(a)
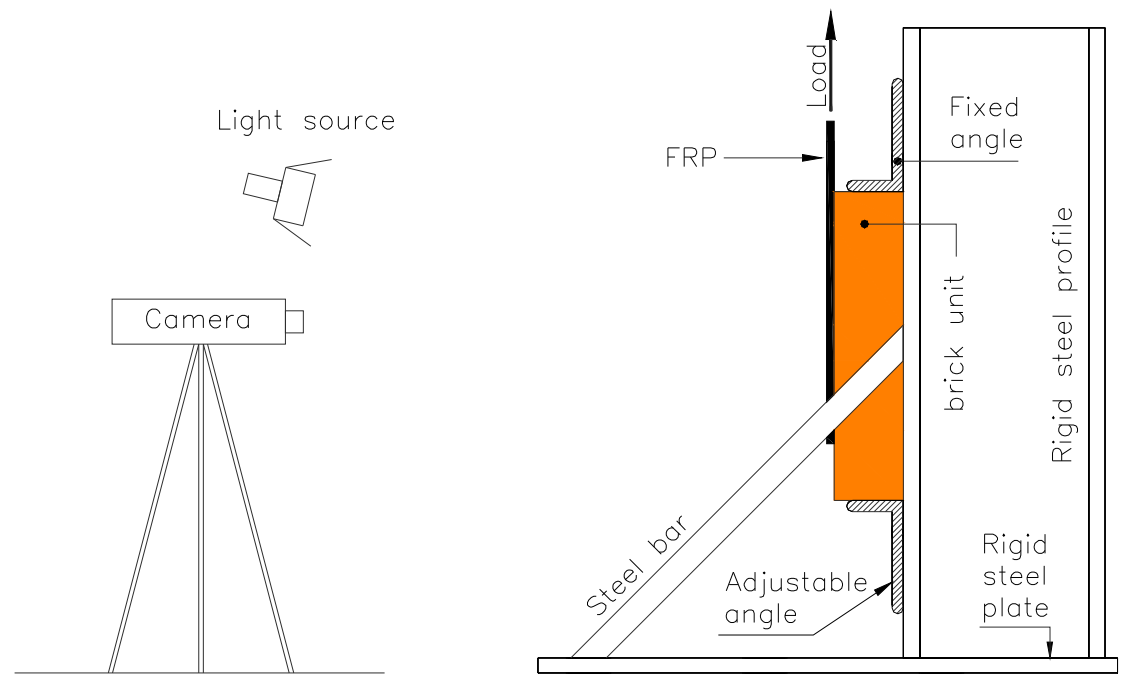

(b)

Fig.6. Tests setup: (a) Tensile tests; (b) Shear bond tests. 


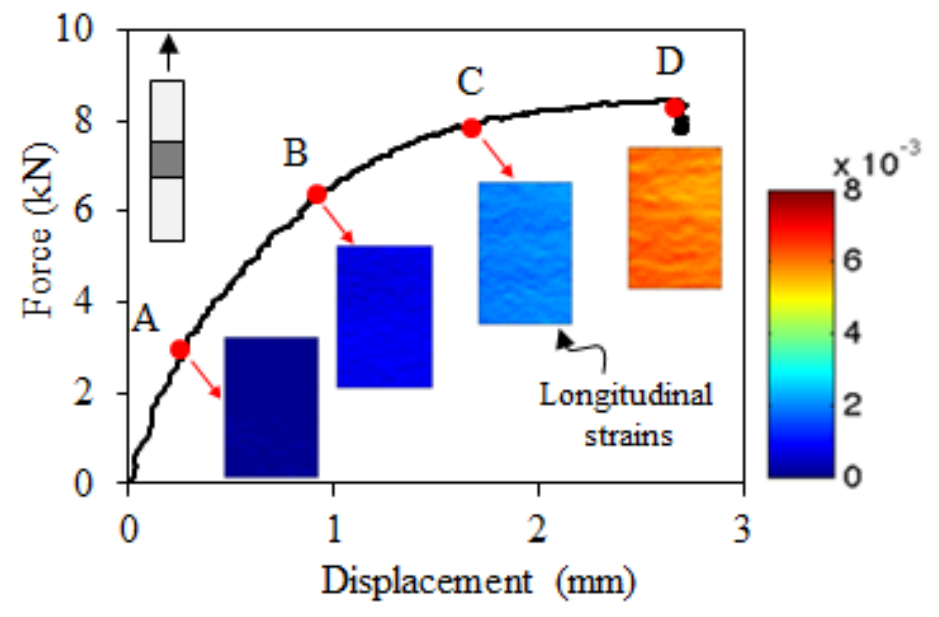

Fig.7. Tensile behavior of the aluminum plate (force-displacement diagram and strains in the ROI). 


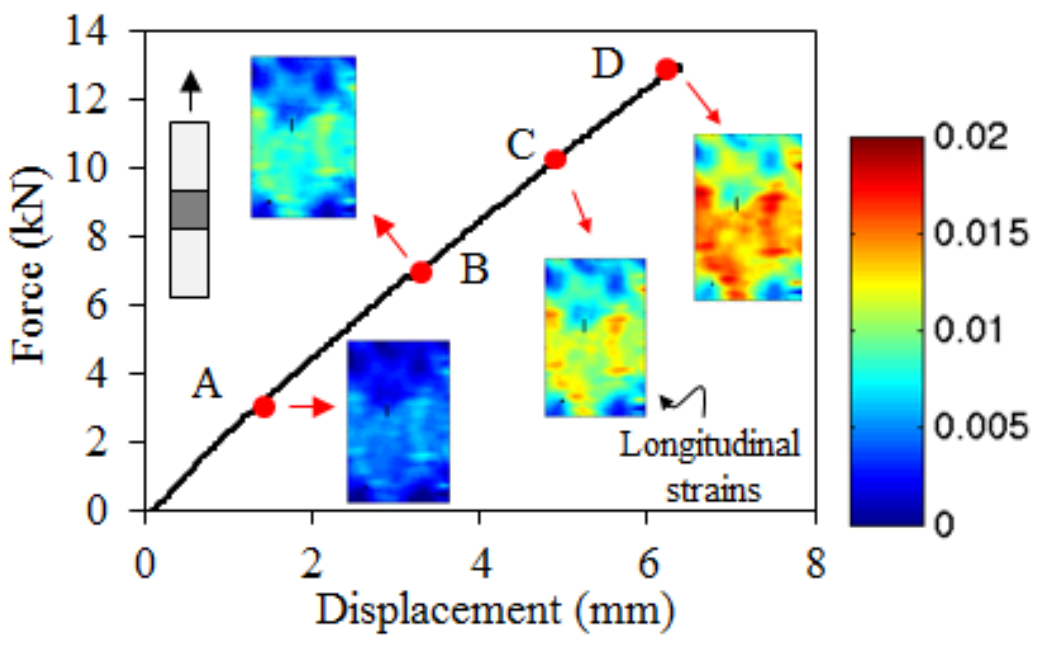

Fig.8. Tensile behavior of the GFRP coupon (force-displacement diagram and strains in the ROI). 


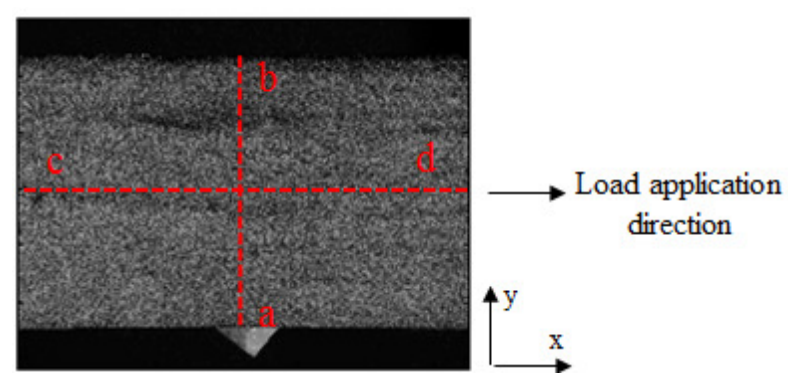

(a)
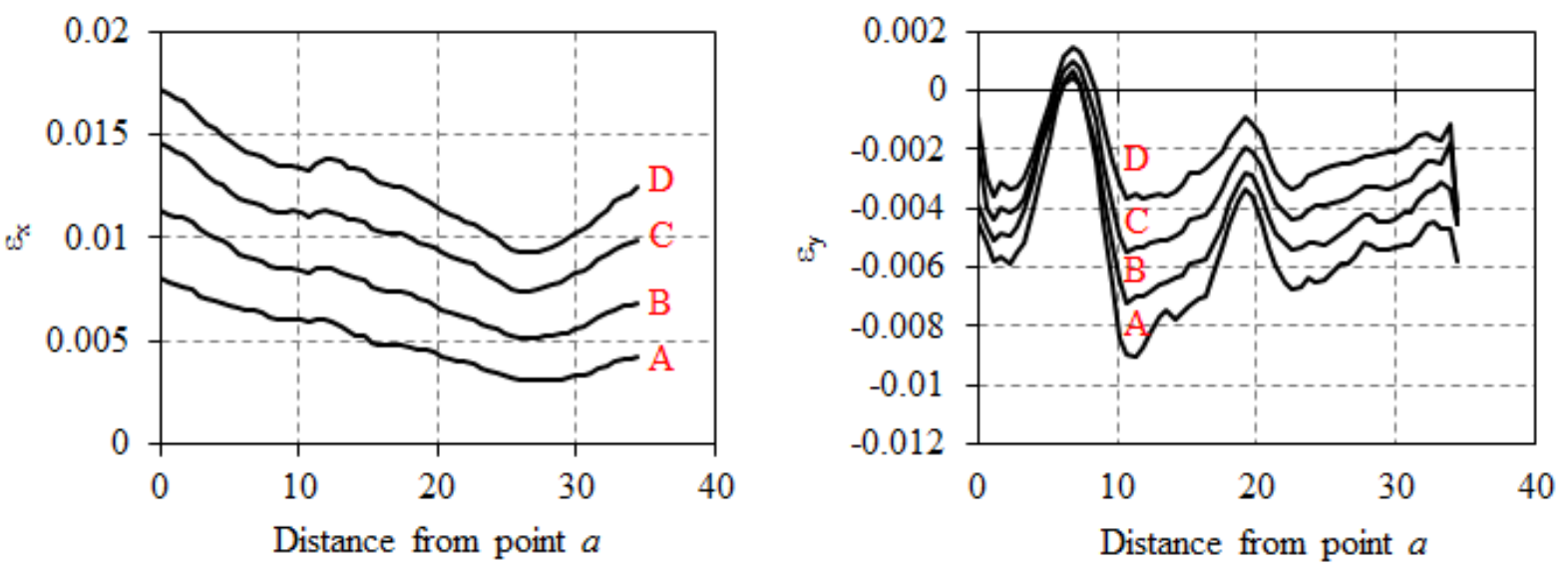

(b)
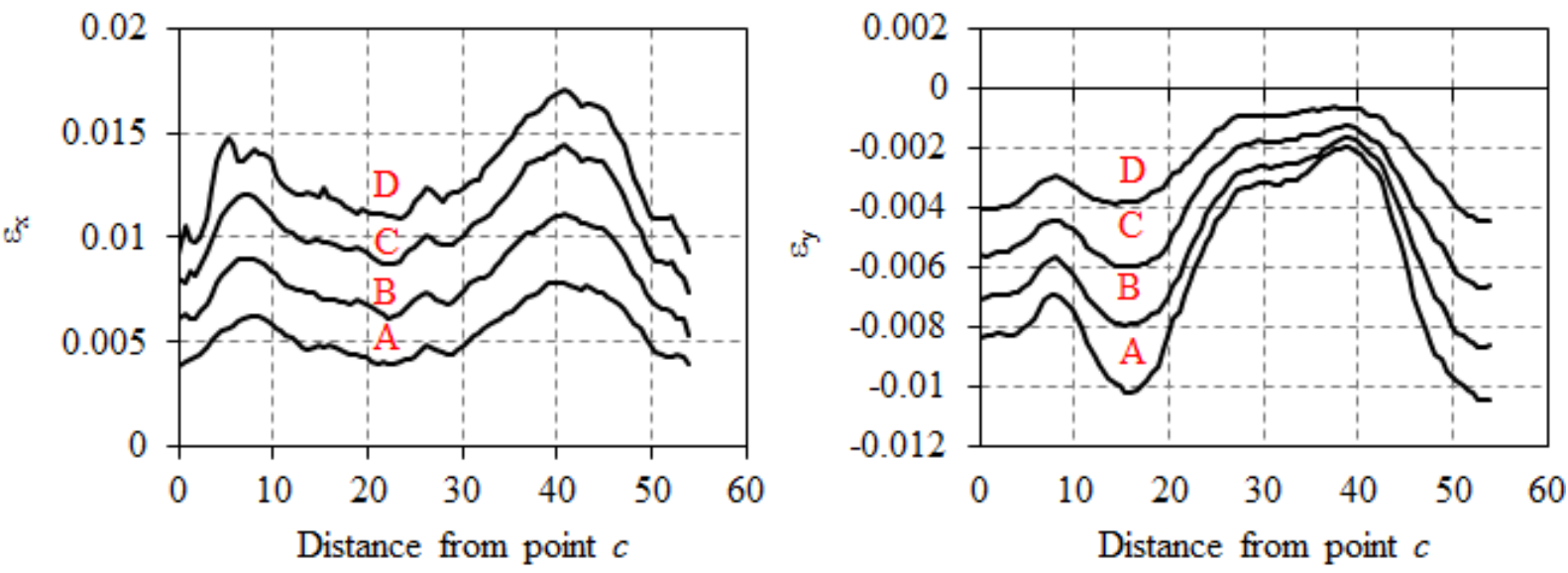

(c)

Fig.9. Strain profiles in the GFRP coupon at different load levels (A to D in Fig.8): (a) speckle pattern; (b) strain profiles along line a-b; (c) strain profiles along line c-d. 


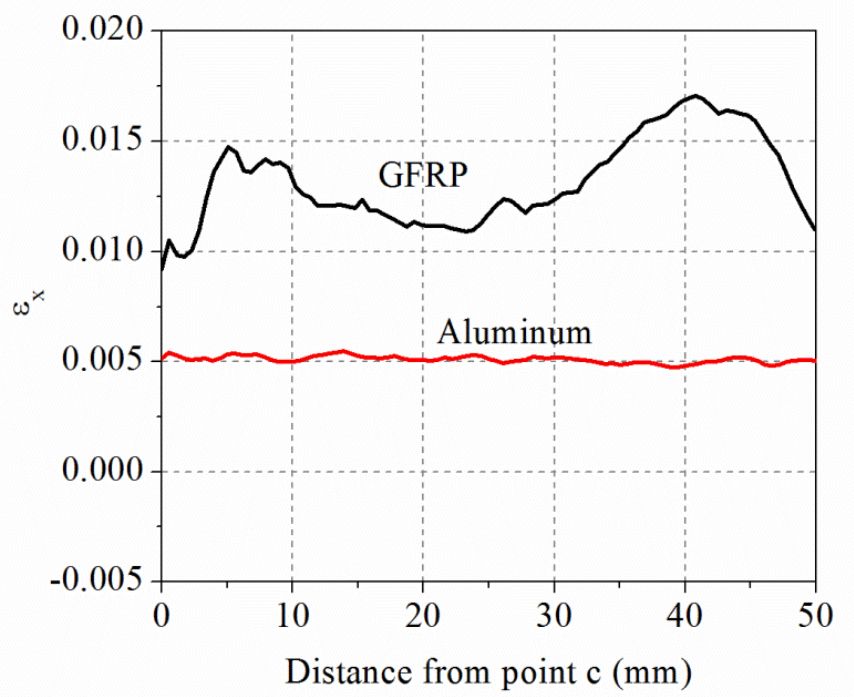

Fig.10. Comparison of longitudinal strains along section c-d between GFRP coupon and aluminum plate for the same load level. 


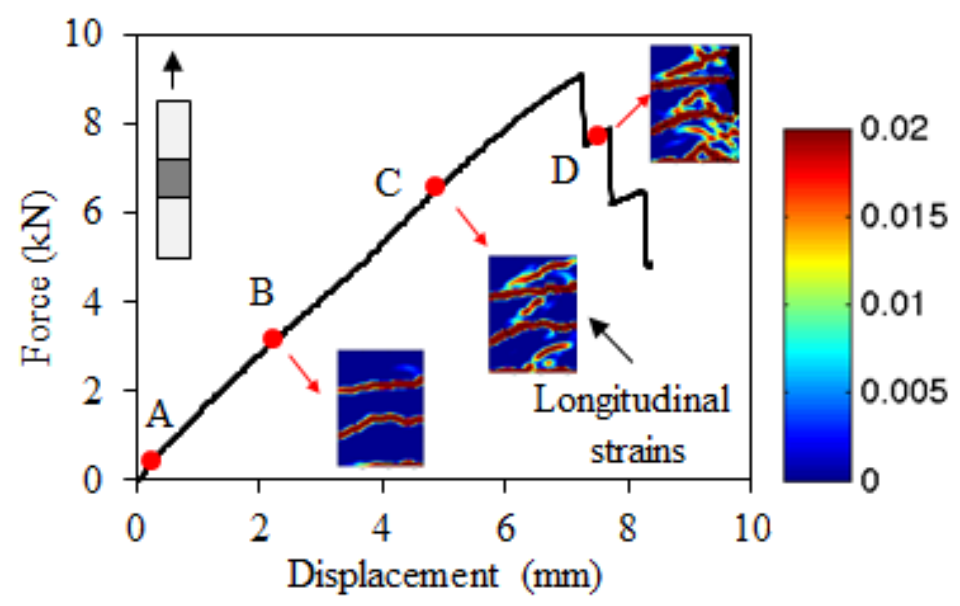

(a)

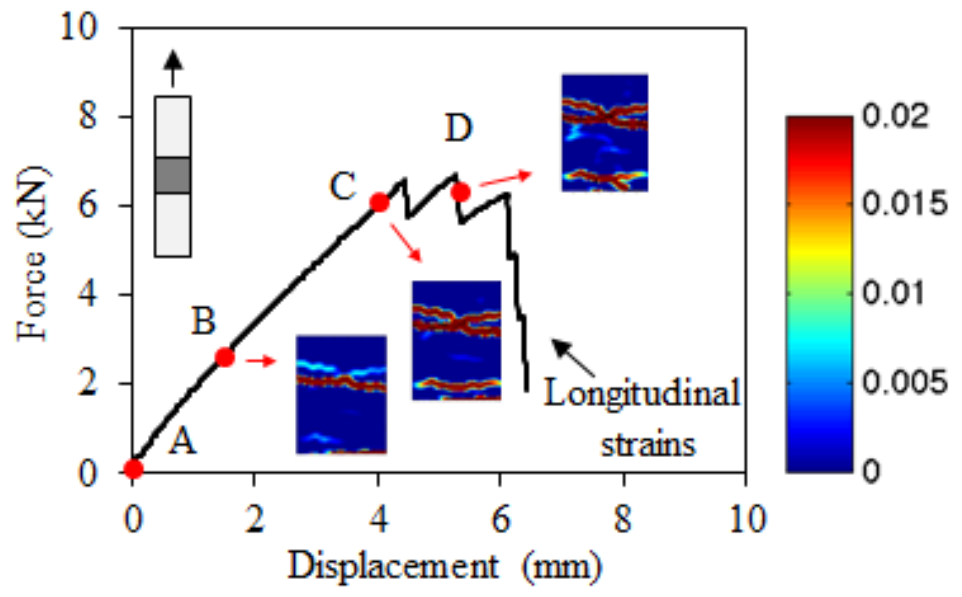

(b)

Fig.11. Load-displacement behavior of the SRG tensile specimens with different mortar thickness in mm (force-displacement diagram and strains in the ROI): (a) SRG-6; (b) SRG-10. 

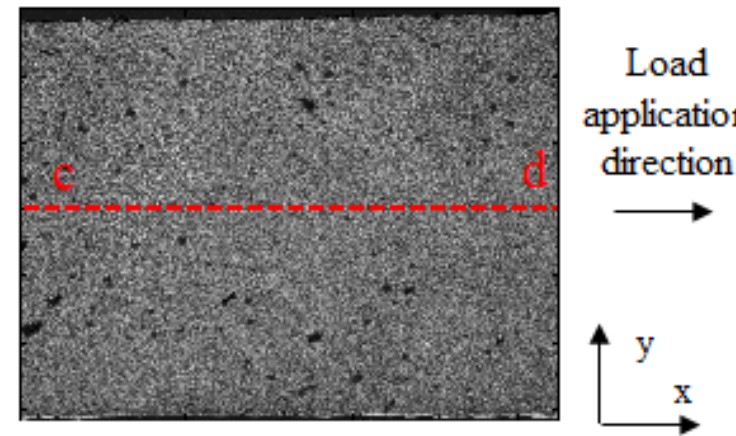

(a)

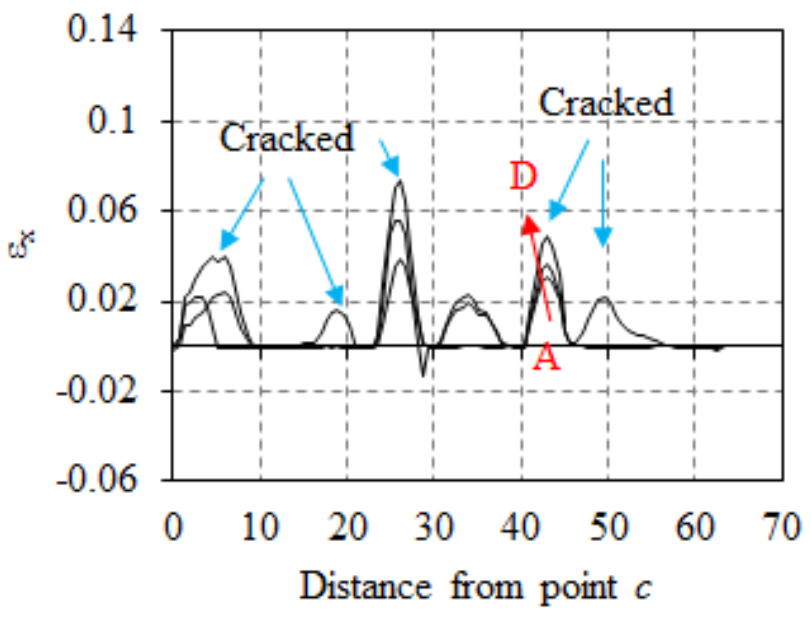

(b)

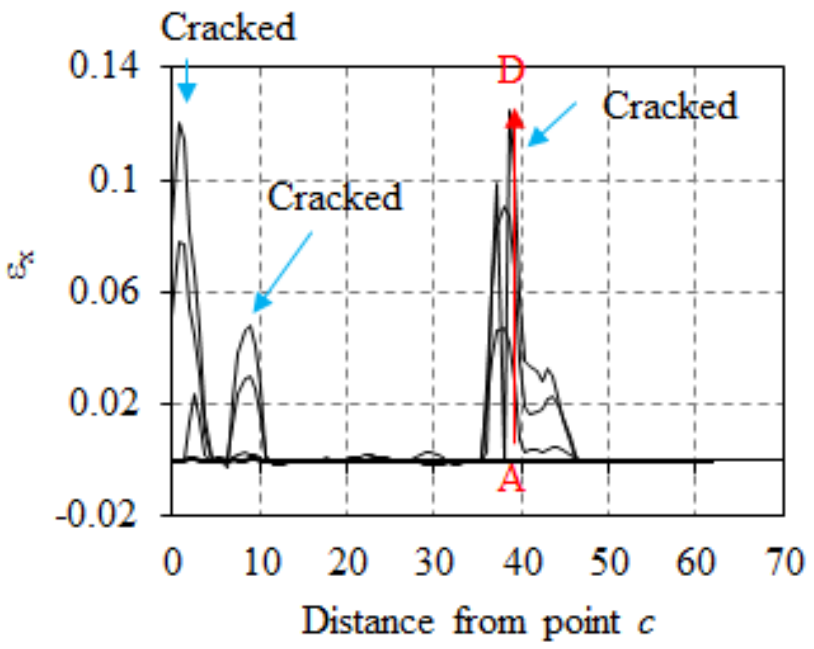

(c)

Fig.12. Longitudinal strains along section c-d in SRG tensile specimens at different load levels (A to D in Fig.11): (a) speckle pattern; (b) SRG-6 specimen; (c) SRG-10 specimen. 

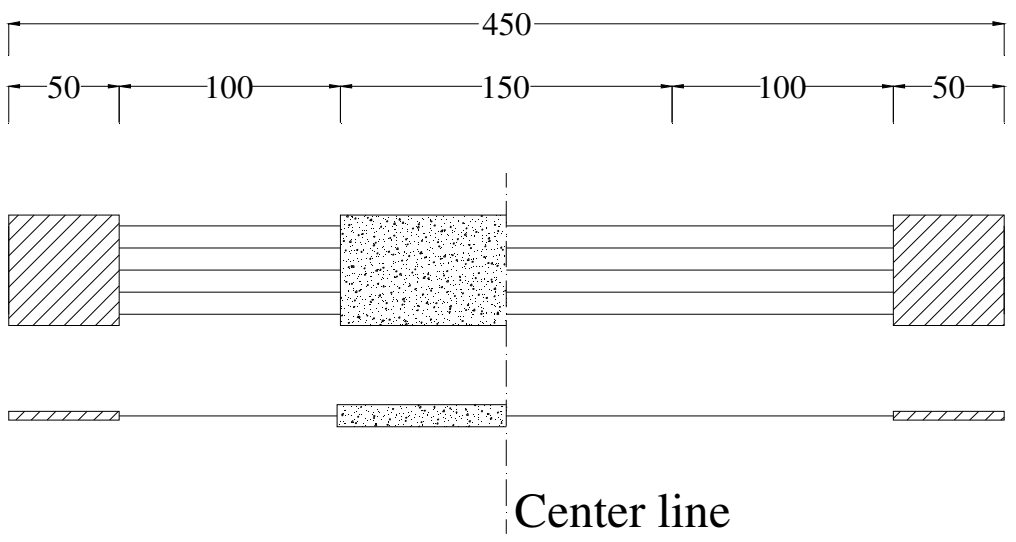

Fig.13. SRG specimens prepared for the feature tracking method (dimensions in $\mathrm{mm}$ ). 


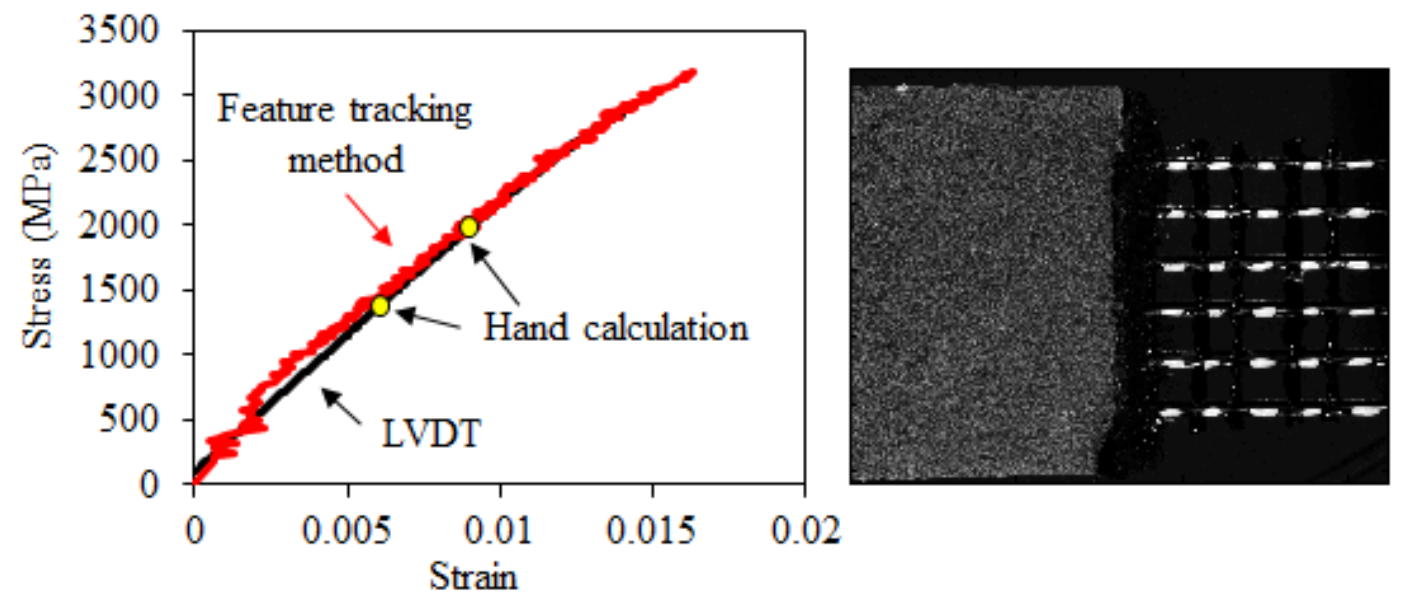

Fig.14. Comparison of strains developed on the steel fibers and mortar surface. 


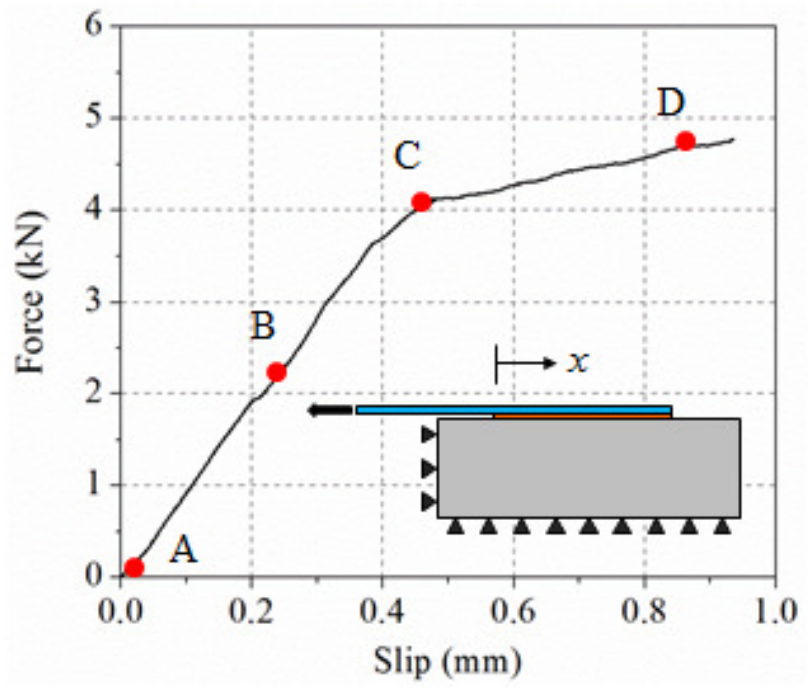

Fig. 15. Typical force-slip behavior of GFRP-strengthened specimen. 

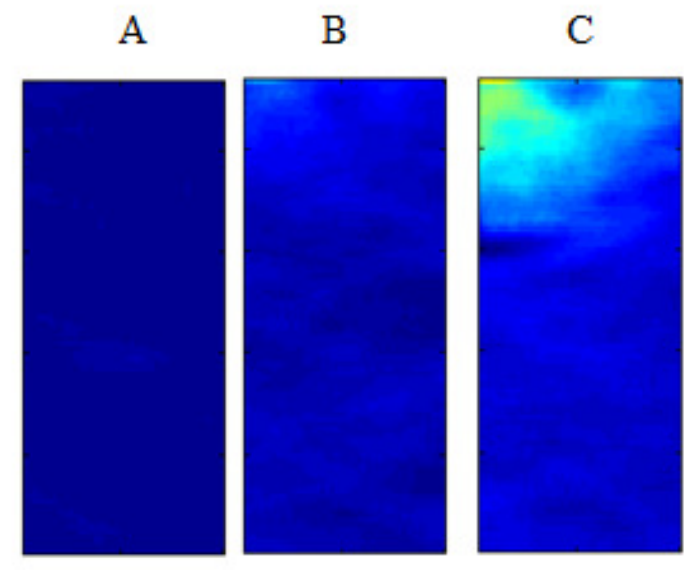

D

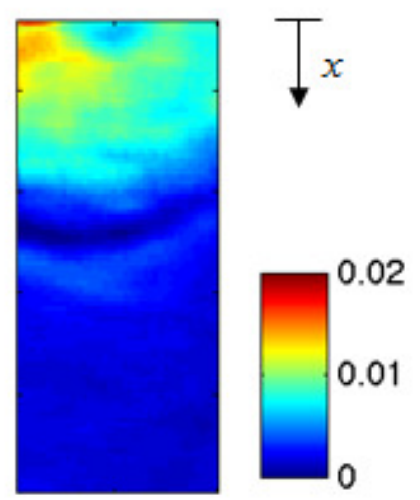

(a)

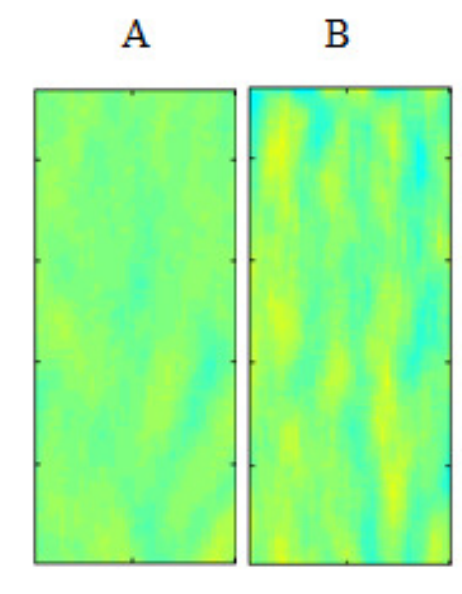

C

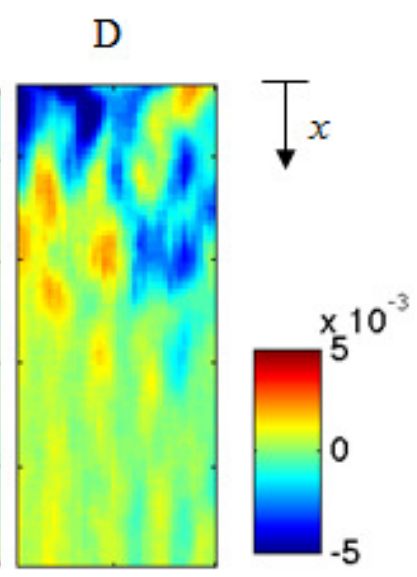

(b)

Fig. 16. Distribution of strains along the bonded area at different load levels (A to D in Fig. 15):

(a) longitudinal strains (b) transversal strains. 

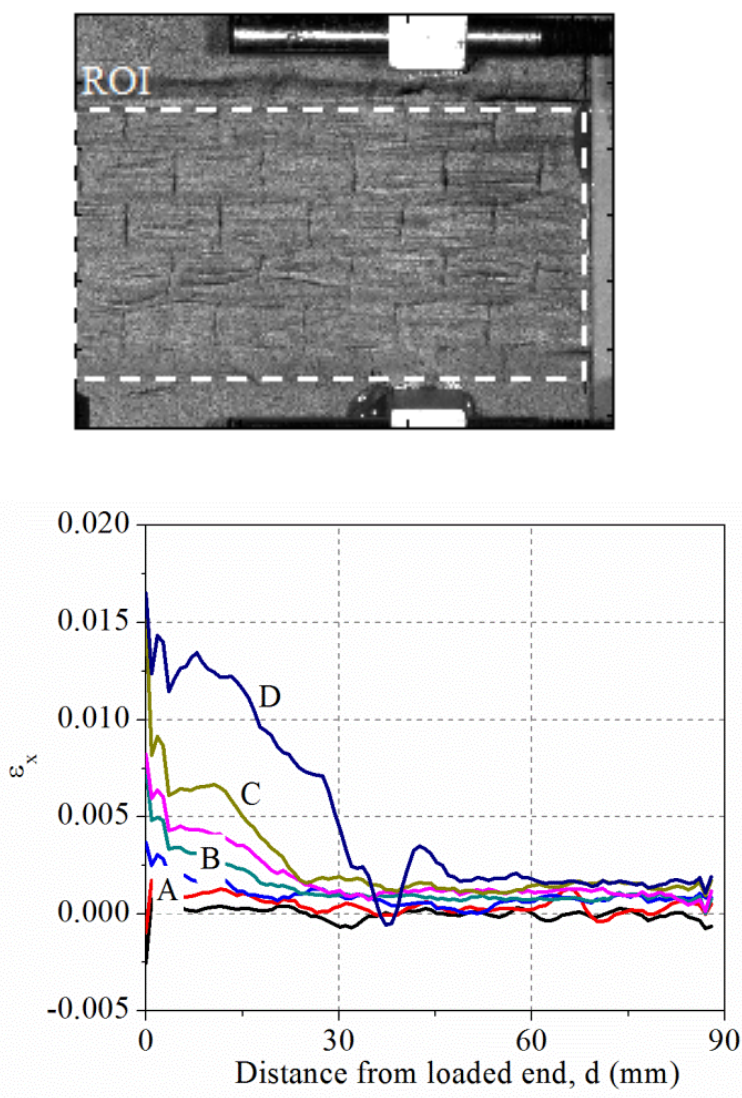

(b)

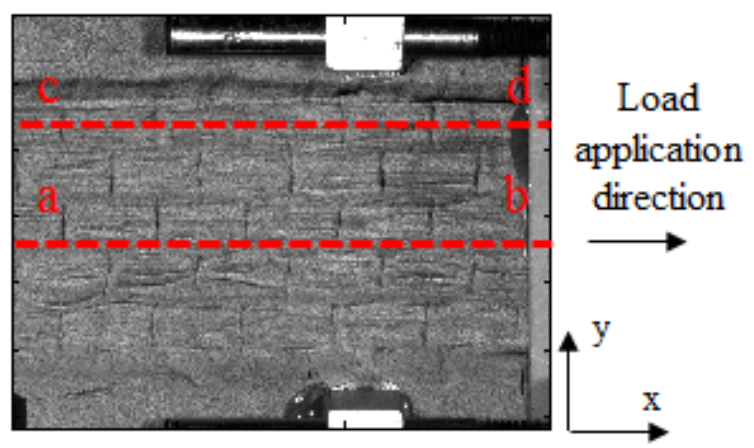

(a)

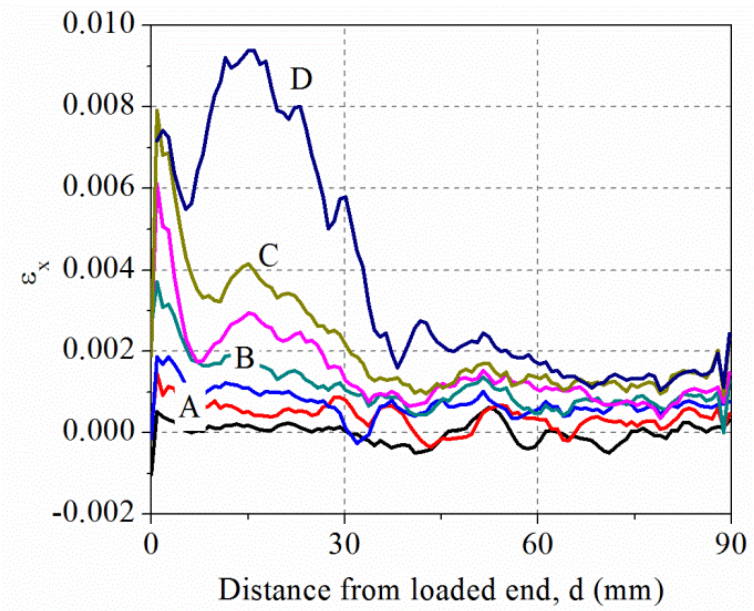

(c)

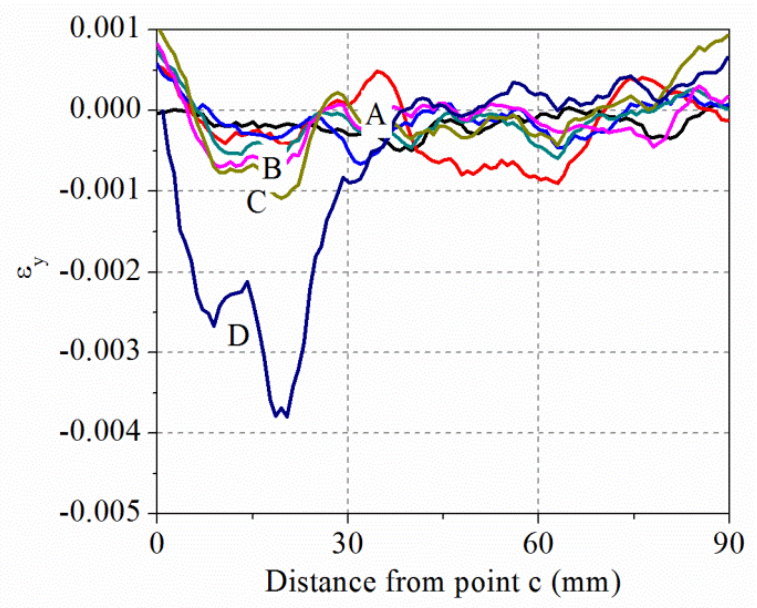

(d)

Fig.17. Strain profiles in GFRP-strengthened brick specimen: (a) speckle pattern; (b)

longitudinal strains along section a-b; (c) longitudinal strains along section c-d; (d) transversal strains along section c-d. 


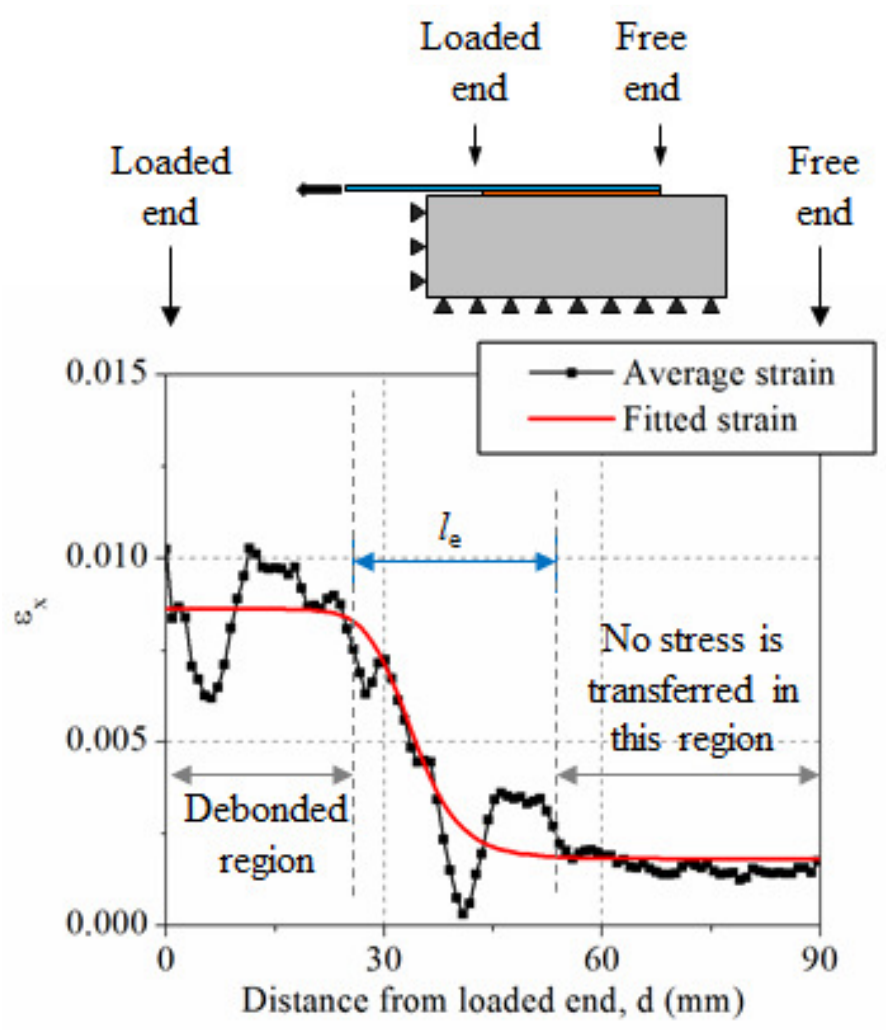

Fig.18. Average longitudinal strain along FRP middle section (sec. a-b in Fig.17) and the effective bond length $l_{e}$. 


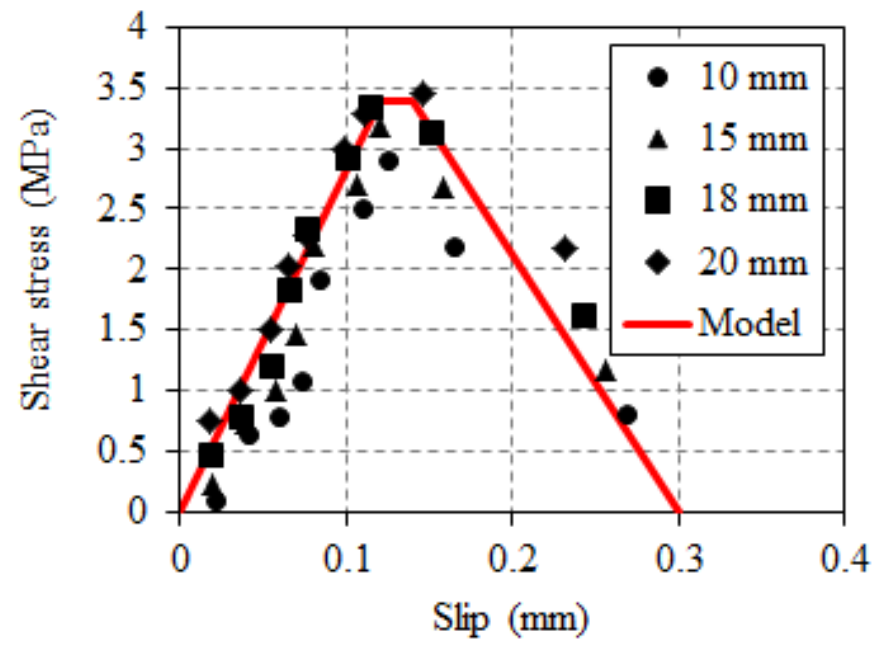

Fig.19. Bond-slip behavior of GFRP-strengthened brick. 